\title{
MEGACÓLON TÓXICO FATAL POR CYTOMEGALOVIRUS EM PACIENTE COM RETOCOLITE ULCERATIVA IDIOPÁTICA: relato de caso e revisão de literatura
}

\author{
Sérgio Ossamu IOSHII ${ }^{1}$, Viviane TEIXEIRA ${ }^{2}$ e Teresa Maria S. FIGUEIREDO ${ }^{3}$
}

RESUMO - Racional - O megacólon tóxico é complicação grave e pouco freqüente na retocolite ulcerativa idiopática. Ocorre, geralmente, em pacientes cuja doença ativa é resistente ao tratamento clínico e, em algumas situações, o fator desencadeante é desconhecido. A infecção pelo cytomelogalovirus em seres humanos em geral é evento subclínico; entretanto, em pacientes imunocomprometidos a primoinfecção ou mesmo a reativação de infecção latente pode ter amplas repercussões clínicas, uma das quais o desencadeamento de megacólon tóxico. Objetivo - Descrever um caso de megacólon tóxico fatal por cytomegalovirose em paciente com retocolite ulcerativa idiopática. Paciente - Masculino, 38 anos, com clínica de diarréia e perda ponderal cuja investigação mostrou tratar-se de retocolite ulcerativa idiopática e para a qual foi instituída terapêutica imunossupressora vigorosa. Resultados - Evoluiu com quadro clínico de megacólon tóxico, sendo submetido a colectomia total. Complicações clínicas culminaram no óbito pós-operatório e o estudo anatomopatológico do cólon revelou doença ativa, associada a ulcerações confluentes na base das quais foram observadas células com alterações características da cytomegalovirose. Conclusão - A cytomegalovirose deve ser considerada como um dos agentes causadores de megacólon tóxico em retocolite ulcerativa.

DESCRITORES - Megacólon tóxico. Infecções por cytomegalovirus. Colite ulcerativa.

\section{INTRODUÇÃOO}

Doença inflamatória difusa da mucosa colônica e retal, de causa ainda desconhecida, a retocolite ulcerativa idiopática (RCUI) tem distribuição bimodal com predomínio no sexo masculino. A busca por sua etiologia tem dirigido investigação para a influência de fatores biológicos, genéticos, psicológicos e imunológicos. Manifesta-se com intensidade variável de diarréia sanguinolenta, dor abdominal e desnutrição, sendo a complicação mais temida o megacólon tóxico. Este, cuja patogênese é explicada por muitas teorias, uma das quais é a da destruição do plexo nervoso mioentérico e da muscular própria, manifesta-se clinicamente por íleo paralítico associado a quadro séptico, resultando em taxas elevadas de mortalidade. Tem-se sugerido como desencadeadores do megacólon tóxico o uso de corticosteróides e a cytomegalovirose. A associação de doença gastrointestinal com cytomegalovirus (CMV) é causa comum de emergência cirúrgica abdominal em pacientes imunocomprometidos.

A infecção por CMV é comum em seres humanos, sendo que a maioria dos casos é subclínica. Aproximadamente 50\% a $80 \%$ dos indivíduos ao redor dos 35 anos de idade apresentam anticorpos anti-CMV circulantes. A cytomegalovirose é observada em todos os segmentos do trato gastrointestinal ${ }^{(7)}$. Há evidências de que pacientes com RCUI apresentam com maior freqüência níveis mais elevados de anticorpos anti-CMV que adultos normais ${ }^{(6)}$. Os relatos de RCUI associada à

Departamento de Patologia Médica da Universidade Federal do Paraná - UFPR; ${ }^{2}$ Faculdade de Medicina da UFPR; ${ }^{3}$ Departamento de Cirurgia da UFPR, Curitiba, PR. Endereço para correspondência: Dr. Sérgio Ossamu Ioshii - Serviço de Anatomia Patológica, Hospital de Clínicas da UFPR - Rua General Carneiro, 181 - $80060-900$ - Curitiba, PR. e-mail: ioshii@hc.ufpr.br 
Ioshii SO, Teixeira V, Figueiredo TMS. Megacólon tóxico fatal por cytomegalovirus em paciente com retocolite ulcerativa idiopática: relato de caso e revisão de literatura

cytomegalovirose são pouco freqüentes e há relação com pior prognóstico.

É apresentado um caso de RCUI, complicada com megacólon tóxico e associada à cytomegalovirose, com revisão de literatura.

\section{RELATO DO CASO}

Paciente masculino, 38 anos, admitido para investigação de diarréia pastosa, sem muco, pus ou sangue, com início 30 dias antes do internamento e emagrecimento de $12 \mathrm{~kg}$ no período. Apresentara episódio semelhante há 8 anos, não sendo submetido a nenhum tratamento. Negava doenças anteriores. Era tabagista há 15 anos e etilista social. Apresentava-se em regular estado geral, eupnêico, anictérico, emagrecido e pálido, com sinais vitais estáveis. Ao exame apresentava como dados positivos, estertores crepitantes, abdome doloroso na região paramediana direita com ruídos hidroaéreos presentes, e membros inferiores com edema e cacifo. De exames complementares verificou-se hipoalbuminemia, anemia microcítica e bastonetose. O exame anti-HIV foi não-reagente. No $2^{\circ}$ dia de internamento, recebeu transfusão sangüínea e foi submetido a retossigmoidoscopia, que revelou ulcerações mucosas em todo o segmento examinado, com úlceras de aproximadamente $1 \mathrm{~cm}$ de diâmetro, além de edema e friabilidade da mucosa. O diagnóstico de RCUI foi confirmado pelo estudo anatomopatológico, em que foram observados focos de inflamação aguda ulcerada, microabscessos crípticos e epitélio regenerativo (Figura 1). Iniciado tratamento clínico com sulfassalazina $40 \mathrm{~g} / \mathrm{dia}$, hidrocortisona $600 \mathrm{mg} / \mathrm{dia}$, metronidazol, cefazolina e gentamicina. No $4^{\circ}$ dia apresentou enterorragia e diarréia esverdeada, recebendo nova transfusão. Sem melhora clínica em 15 dias, foram aumentadas as doses de sulfassalazina e hidrocortisona para 60 e $1 \mathrm{~g} /$ dia, respectivamente. Evoluiu com piora do estado geral, distensão abdominal grave e ascite, e o diagnóstico de megacólon tóxico foi efetuado. O paciente foi submetido a laparotomia exploradora e na sequiência, colectomia total e ileostomia. Ao estudo anatomopatológico do cólon, observou-se dilatação importante de sua luz, com ulcerações mucosas e, ao estudo microscópico, foram identificadas inclusões virais características de CMV em núcleos de células epiteliais e endoteliais (Figura 2). O paciente faleceu no pós-operatório imediato devido a complicações pulmonares, com síndrome da angústia respiratória do adulto e coagulação intravascular disseminada. Não foi possível a realização de necropsia.

\section{DISCUSSÃO}

A RCUI é doença inflamatória difusa que afeta, com maior frequiência, a mucosa do reto e porção distal do cólon. Tem distribuição bimodal, com um primeiro pico de incidência entre os 15 e 20 anos de idade e um segundo, menor, dos 55 aos 60 anos de idade. Sua causa ainda não é conhecida, tendo-se dirigido investigação para agentes bacterianos e viróticos, além de fatores genéticos, psicológicos e imunológicos. Esta doença pode manifestar-se de forma leve a fulminante e se caracteriza por quadro clínico progressivamente intenso de diarréia sanguinolenta, dor abdominal e desnutrição. O megacólon tóxico é a complicação mais sombria da doença e se apresenta com distensão abdominal, dor e desaparecimento dos ruídos intestinais, além de febre, taquicardia e sinais de desequilíbrio hidroeletrolítico. O índice de mortalidade varia de $20 \%$ a $30 \%$ dos casos. Há muitas teorias que explicam a patogênese do megacólon tóxico que ocorre em pacientes com RCUI e incluem destruição do plexo nervoso mioentérico, necrose da muscular própria, uso de agentes anticolinérgicos e narcóticos e mesmo a ação de corticosteróides como potencializadores dessa complicação.

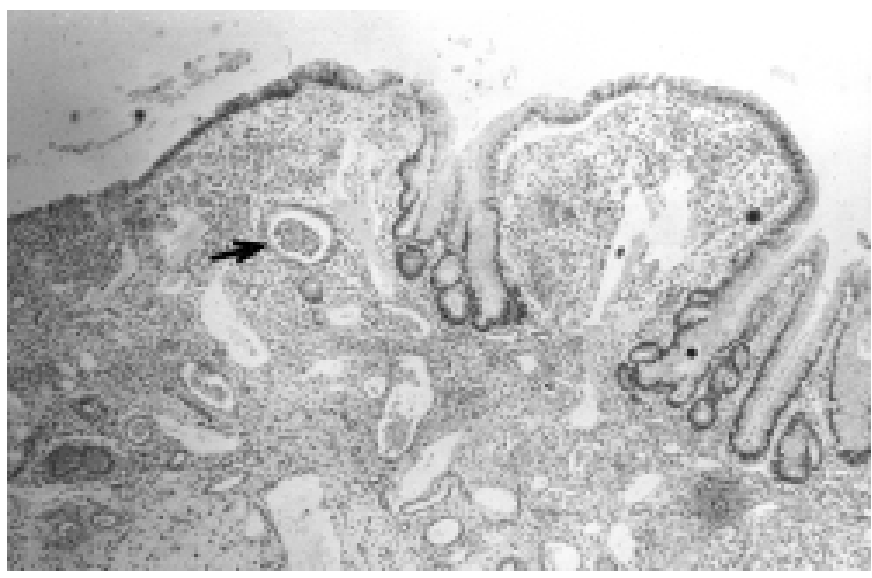

FIGURA 1 - Retocolite ulcerativa em atividade inflamatória, com criptas regenerativas $\left({ }^{*}\right)$ e microabscesso neutrofílico (seta). (HE, 100x)

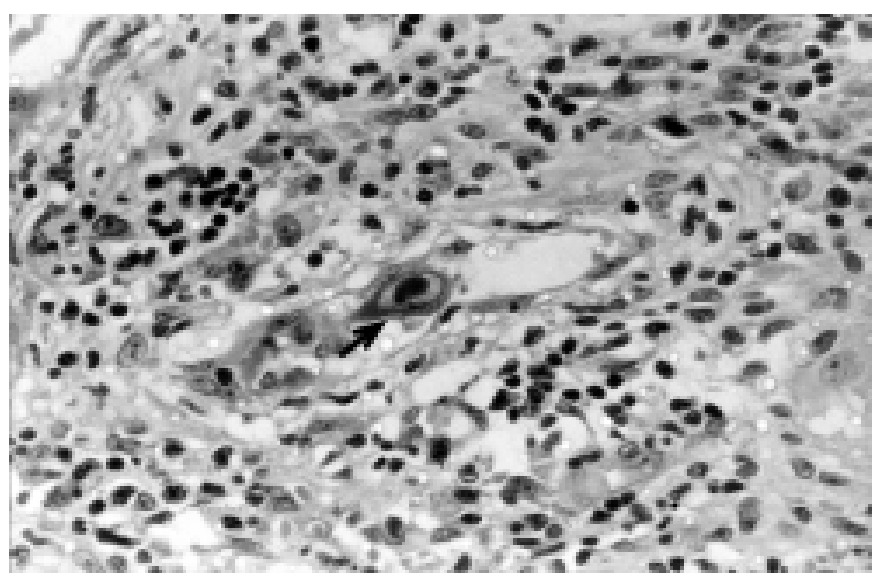

FIGURA 2 - Célula endotelial com citoplasma amplo, granular e núcleo aumentado de volume, com inclusão viral central envolta por halo claro e cromatina condensada na membrana nuclear caracterizando cytomegalovirose (seta). (HE, 400x) 
A doença gastrointestinal por $\mathrm{CMV}^{(12)}$ é uma das causas comuns de emergência cirúrgica abdominal em pacientes imunodeprimidos. A cytomegalovirose tem sido mostrada como complicadora de doença inflamatória intestinal ${ }^{(13)}$ e pode estar associada ao megacólon tóxico $^{(1,2,3)}$.

Doença gastrointestinal por CMV está presente em processos ulcerativos e erosivos. Podem ocorrer em qualquer localização do trato gastrointestinal, desde a boca até o reto ${ }^{(4,8,9,10,11,12,14,15)}$, mas os sítios mais freqüentes são o cólon ascendente $(2,3 \%)$, o cólon transverso $(2,0 \%)$, o ceco $(1,3 \%)$ e o reto $(0,8 \%)$. É rara a infecção por CMV na árvore biliar.

Em pacientes imunocompetentes, a CMV gastrintestinal pode ser devida à infecção primária, transfusão sangüínea ou transmissão sexual. Vale ressaltar que a CMV em íleo terminal pode mimetizar a doença de Crohn, desde o ponto de vista clínico, endoscópico ou radiológico.
A análise histopatológica define o diagnóstico, sendo caracterizada por células infectadas com tamanho de 25 a $35 \mu \mathrm{m}$ de diâmetro, contendo inclusão eosinofílica intranuclear, rodeada por halo claro e cromatina granular, além da possível associação com inclusões citoplasmáticas basofílicas ${ }^{(5)}$. A utilização de anticorpos monoclonais anti-CMV por meio de técnicas como a imunoperoxidase e imunofluorescência, e a hibridização in situ aumentam a sensibilidade da análise histopatológica.

\section{AGRADECIMENTOS}

Os autores agradecem aos Drs. Vanda Fátima Rebuffi, Ewerton Marques Maggio e Yolanda Silva pela participação na descrição deste caso.

Ioshii SO, Teixeira V, Figueiredo TMS. Fatal toxic megacolon due to cytomegalovirosis in a patient with ulcerative colitis: case report and review. Arq Gastroenterol 2002;39(2):111-113

ABSTRACT - Background - The toxic megacolon is a rare and severe complication of ulcerative colitis. In general it complicates patients with active colitis that are resistant to clinical treatment and, in some cases, the developing factor is unknown. Cytomegalovirus infection in humans in general is a subclinical condition. However, in patients with immunodeficiency the primary infection or the reactivation of latent infection could have enormous clinical effects. One of these effects is the toxic megacolon. Aim - To report a case of fatal toxic megacólon due to cytomegalovirosis in a patient with ulcerative colitis. Patient - A male patient, 38 years old, with complaints of diarrhea and weight loss. The diagnosis of ulcerative colitis was made and a vigorous immunossupressive therapy was performed. Results - Due to the evolution to a toxic megacolon the patient was submitted to colectomy. In the post-operatory period there were severe clinical complications and the patient died. The pathological study of the colon revealed active ulcerative colitis, associated with confluent ulcerations and numerous cells with cytomegalic nuclear inclusions. Conclusion - The cytomegalovirosis must be considered as one of the causal agent of toxic megacolon in ulcerative colitis.

HEADINGS - Megacolon, toxic. Cytomegalovirus infections. Colitis, ulcerative.

\section{REFERÊNCIAS BIBLIOGRÁFICAS}

1. Berk T, Gordon SJ, Choi HY, Cooper HS. Cytomegalovirus infection of the colon: A possible role in exacerbations of inflammatory bowel disease. Am J Gastroenterol 1985;80:355-60.

2. Cooper HS, Raffensper EC, Jonas L, Fitts WT. Cytomegalovirus inclusions in patients with ulcerative colitis and toxic dilatation requiring colinic resection. Gastroenterology 1977;72:1253-6.

3. Foucar E, Mukay K, Foucar K, Sutherland DE, van Buren CT. Colon ulceration in lethal cytomegalovirus infection. Am J Clin Pathol 1981;76:788-801.

4. Frank D, Raich RF. Intestinal perforation associated with cytomegalovirus infection in patients with acquired immune deficiency syndrome. Am J Gastroenterol 1984;79:201-5

5. Goodgame RW. Gastrointestinal cytomegalovirus disease. Ann Intern Med 1993;119:924-35

6. Goodman ZD, Boitnott JK, Yardley JH. Perforation of the colon associated with cytomegalovirus infection. Dig Dis Sci 1979;24:376-80.

7. Henson D. Cytomegalovirus inclusion bodies in the gastrointestinal tract. Arch Pathol 1972;93:477-82.

8. Jacobson MA, Mills J. Serious cytomegalovirus disease in the acquired immunedoficiency syndrome (AIDS). Clinical findings, diagnosis and treatment. Ann Intern Med 1988;108:585-94.
9. Kanas RJ, Jensen JL, Abrams AM, Wuerker RB. Oral mucosal cytomegalovirus as a manifestation of the acquired immune deficiency syndrome. Oral Surg Oral Med Pathol 1987;64:183-9.

10. Kram HB, Shoemaker WC. Intestinal perforation due to cytomegalovirus infection in patients with AIDS. Dis Colon Rectum1990;33:1037-40.

11. Marcusen DC, Sooy CD. Otolaryngologic and head and neck manifestations of acquired immunodeficiency syndrome (AIDS). Laringoscope 1985;95:401-5.

12. Meilseman MS. Cytomegalovirus colitis: report of the clinical, endoscopic, and pathologic findings in two patients with the acquired immune deficiency syndrome. Gastroenterology 1985;88:171-5.

13. Rene E, Marche C, Chevalier T, Rouzioux C, Regnier B, Saimot AG, Negesse Y Matheron S, Leport C, Wolff B. Cytomegalovirus colitis in patients with acquired immunodeficiency syndrome. Dig Dis Sci 1988;33:741-50.

14. Robey SS, Gage WR, Kuhajda FP. Comparison of immunoperoxidase and DNA in situ hybridazation techniques in the diagnosis of cytomegalovirus colitis. Am J Clin Pathol 1988;89:666-71.

15. Sidi S, Graham JH, Razvi SA, Banks PA. Cytomegalovirus infection of the colon associated with ulcerative colitis. Arch Surg 1979;114:857-9. 